\title{
BMJ Open (Un)Spoken realities of living with axial spondyloarthritis: a qualitative study focused on couple experiences
}

\author{
Kerry Raybone, ${ }^{1}$ Hannah Family, ${ }^{2}$ Raj Sengupta, ${ }^{3}$ Abbie Jordan ${ }^{\oplus 4}$
}

To cite: Raybone K, Family H, Sengupta R, et al. (Un) Spoken realities of living with axial spondyloarthritis: a qualitative study focused on couple experiences. BMJ Open 2019;9:e025261. doi:10.1136/ bmjopen-2018-025261

- Prepublication history and additional material for this paper are available online. To view please visit the journal (http:// dx.doi.org/10.1136/bmjopen2018-025261)

Received 7 July 2018 Revised 26 April 2019 Accepted 12 June 2019

Check for updates

(C) Author(s) (or their employer(s)) 2019. Re-use permitted under CC BY-NC. No commercial re-use. See rights and permissions. Published by BMJ.

${ }^{1}$ Psychology, University of Bath, Bath, UK

${ }^{2}$ Pharmacy and Pharmacology, University of Bath, Bath, UK

${ }^{3}$ The Royal National Hospital for Rheumatic Diseases, Bath, UK

${ }^{4}$ Psychology, Centre for Pain Research, University of Bath, Bath, UK

Correspondence to

Dr Abbie Jordan;

a.I.jordan@bath.ac.uk

\section{ABSTRACT}

Objective Axial spondyloarthritis is a long-term rheumatic condition. The symptoms, including pain, can impact on the daily life routines and psychological well-being of individuals that are diagnosed with axial spondyloarthritis (axSpA). Partners are often a main source of support for individuals who manage a long-term condition and they can also be affected by the illness experience, often themselves reporting elevated levels of emotional distress. Few qualitative studies have explored the impact of axSpA on partner relationships. This study addresses the social context of axSpA by investigating the experiences for both individuals with axSpA and their partners.

Design Semistructured individual telephone interviews analysed using thematic analysis at a dyadic partner level. Setting Participants were recruited from the social media pages of a UK-based axSpA-specific charity.

Participants Nine heterosexual partner dyads (23-65 years), who were currently cohabiting, comprising nine individuals diagnosed with axSpA ( $\mathrm{n}=6$ females) and nine partners ( $\mathrm{n}=3$ females).

Results Three themes 'Perceived relational closeness', 'Playing third wheel to axSpA' and 'Tensions surrounding a carer-type role' were identified. The findings illustrate how living with axSpA can influence closeness between partners and dominate daily decisions, particularly surrounding leisure activities. Partners commonly adopted a carer-type role, despite many individuals with axSpA expressing desire for a greater sense of autonomy. Conclusions This study provides an important insight into the lived experiences of both individuals with axSpA and their partners. Findings highlight the social context of managing a long-term condition and suggest the need for including partners within consultations, and the need for support provision for partners.

\section{INTRODUCTION}

Axial spondyloarthritis (axSpA) is a group of rheumatic conditions primarily affecting the spine and sacroiliac joints ${ }^{12}$ with chronic pain being the leading symptom. ${ }^{3}$ The long-term condition predominantly affects males with symptoms typically developing prior to the age of $30 .{ }^{4}$ Major daily living challenges associated with the condition include reduced functional ability, fatigue and depression. ${ }^{5-7}$

\section{Strengths and limitations of this study}

In-depth qualitative interviews generated rich and meaningful data providing rich insights into partner dyadic experiences of axial spondyloarthritis (axSpA).

- The first study to recruit both individuals with axS$\mathrm{pA}$ and their partners, enabling exploration of both similarities and differences between perceptions regarding living with axSpA.

- As participants were recruited from the social media pages of a single UK-based axSpA charity, results represent accounts from participants who sought support from this organisation, suggesting potentially different accounts from participants who had not sought contact with the condition specific charity.

- Recruitment of dyads required a level of communication between partners to discuss participation, with the possibility of couples with poorer relationships being less likely to participate in the study.

- As dyads comprised only White British heterosexual couples, participants' experiences may not represent those of other types of couples

Reducing the progression of functional disability in individuals with axSpA is an important clinical and research focus. Studies have suggested that social support can play an important role, noting that social support has been shown to lessen the rate of functional disability progression over the course of 5 years in individuals with axSpA. ${ }^{8}$ Specific to partner relationships, the rheumatoid arthritis (RA) literature has highlighted the importance of examining partner relationships with regard to influencing health outcomes which, to the best of our knowledge, is currently non-existent within the axSpA literature. Due to similarities between RA and axSpA, with both being inflammatory rheumatic conditions associated with increased pain and related disability, ${ }^{9}{ }^{10}$ the RA literature is considered here as a helpful context in which to consider the importance of partner relationships in axSpA. One Canadian quantitative study identified that greater satisfaction with spousal 
responses was associated with reduced feelings of helplessness in individuals with RA. ${ }^{11}$ Nonetheless, partner support is not always protective, with studies highlighting associations between inaccurate estimations of their partner's pain or fatigue and increased levels of anxiety and depression in individuals with RA. ${ }^{12}$ To explore partner issues further, the concept of dyadic coping has been identified, referring to the numerous ways that couples may communicate during the management of illness-related stressors. ${ }^{13}$ Specifically, the cognitive transactional model of dyadic coping with a long-term health condition highlights how a couple may assign illness ownership as 'my', 'your' or 'our' problem before appraising how to manage the condition. ${ }^{14}$ Dyadic coping can be positive or negative in nature, acknowledging either collaboration or withdrawal between partners. ${ }^{14-16}$ If the coping strategy is perceived as effective this can increase dyadic efficacy, a sense of confidence with working together, and influence relationship outcomes. ${ }^{14}$ Reflective of this increased focus on partners, an evidence base is growing, demonstrating the increased effectiveness of couple-focused behaviour change interventions compared with usual care and individual interventions for individuals with long-term conditions. ${ }^{17}$

Qualitative studies have also begun to examine the social context of axSpA. Individuals with axSpA report restrictions in their ability to engage in physical and social activities $^{1819}$ and experience sexual problems. ${ }^{20-22}$ To contrast these negative outcomes, a qualitative study has demonstrated strengthened partner relationships. ${ }^{23}$ Yet, a study using a questionnaire to examine social roles has shown that while individuals with axSpA place greater importance on partner relationships compared with a control group, their satisfaction with the ability to participate in this role is lower. ${ }^{24}$ Studies examining partner relationships within axSpA have typically only included the views of the individual with axSpA, excluding partner experiences. One exception included a quantitative study using psychometrically robust measures of psychological well-being, physical well-being and depression, to find that spouses reported significantly reduced social functioning and general health perceptions, and increased levels of depression, respectively, compared with spouses of healthy individuals. ${ }^{25}$ However, due to the restrictions associated with self-report questionnaires, this study was unable to provide an in-depth exploration into how and why partners of individuals with axSpA report a reduced quality of life. Considering the potential challenges of having a partner with axSpA, it is problematic that the literature has typically focused on studying the individual with axSpA in isolation. ${ }^{18}$

Consequently, using an idiographic exploratory qualitative approach, ${ }^{26}$ this study aims to explore how and why axSpA impacts on partner relationships according to individuals with axSpA and their partners.

\section{METHODS}

\section{Sample and recruitment}

Sampling was purposive to recruit dyads comprising individuals diagnosed with $\operatorname{axSpA}(n=9)$ and their partners $(\mathrm{n}=9)$. It was anticipated that between 5 and 10 dyads would be recruited based on previous related qualitative research studies, ${ }^{27-29}$ and the scope of the study which was conducted as part of a 4-month Masters placement. A total of 18 participants (nine partner dyads) were recruited via study invitations placed by a UK-based axSpA-specific charity on their social media pages (Facebook and Twitter). Interested participants contacted the researcher to receive an information sheet, prior to providing fully informed written consent. Eligibility criteria required individuals to be aged at least 18 years, speak English fluently and report no cognitive impairments. Thirty-one individuals requested information about the study, with 22 individuals subsequently not participating. Reasons for non-participation included having a partner who did not wish to take part and feeling unwell.

\section{Patient and public involvement}

The development of the research question was informed by earlier work conducted with patients with axSpA. Participants were not involved in the design, recruitment or conduct of the study. Participants will be informed via email about the publication of results.

\section{Data collection}

Data were collected via in-depth, individual semistructured telephone interviews by KR (female Masters level psychology student), until data saturation was reached as defined by no new information being attained at data collection. ${ }^{30-32}$ Telephone interviews have been shown to be optimal choices for collecting rich data, examining sensitive topics and for facilitating recruitment of geographically diverse participants such as those with rare conditions such as axSpA. ${ }^{33-35}$ Participants were interviewed individually to prevent direct influence from their partner. ${ }^{36}$ Topic guides were generated by identifying the main areas of interest ${ }^{37}$ and surveying the literature. ${ }^{12}$ Interview questions were open-ended, asking participants about the impact of axSpA on daily life and partner relationships. Separate yet similar topic guides were devised for the individuals with axSpA and partners (see online supplementary table 1).

Probe questions were used to prompt for further depth where appropriate ${ }^{38}$ Interview duration ranged between 25 and $73 \mathrm{~min}$, with interviews audio-recorded and transcribed verbatim. Telephone interviews have been reported to induce greater levels of fatigue in participants compared with face-to-face interviews, with an interview duration of around $30 \mathrm{~min}$ considered to be appropriate for a telephone interview. ${ }^{39}$

Prior to interviews, participants completed a brief online survey via Qualtrics (an online survey platform) to provide basic demographic information along with informed consent.

\section{Data analysis}

Interview transcripts were prepared in a Word document. All individual interview transcripts were uploaded into 
NVivo version $11^{40}$ (qualitative data analysis software) and analysed using thematic analysis $(\mathrm{TA})^{41}$ at all stages of the analytical process. This enabled a rich understanding of new data through exploration alongside the incorporation of past research. ${ }^{42} \mathrm{TA}$ is a flexible method which allowed for an inductive approach to coding and analysis of the idiographic focus on dyads' experiences. Braun and Clarke's ${ }^{41}$ stages of TA, which involved familiarisation, coding, producing, reviewing and labelling themes, were followed iteratively from a descriptive to interpretative analysis. ${ }^{43}$ Subsequently, accounts of individuals' with axSpA were compared with partner accounts to note similarities and differences. ${ }^{44} \mathrm{~A}$ reflexive journal was used throughout data collection and analysis to prevent biased interpretations of the data from previous knowledge of having met patients with axSpA. Analysis was conducted by $\mathrm{KR}$, with themes reviewed by $\mathrm{AJ}$ and $\mathrm{HF}$ to ensure reliability. The consolidated criteria for reporting qualitative research (COREQ) ${ }^{45}$ were followed and Yardley's ${ }^{46}$ criteria for assessing the quality of qualitative research were met. Previous studies were reviewed (sensitivity to context) and Braun and Clarke's ${ }^{42} 15$-point guidelines on conducting TA were followed (commitment and rigour). Further, a fit between the research question and choice of TA was ensured (coherence). Finally, knowledge about partner relationships within the context of axSpA was enhanced (impact and importance).

\section{RESULTS}

The sample comprised nine individuals with axSpA and nine partners. All couples were heterosexual and white British/Scottish, with an age range of 23-65 years. Six individuals with axSpA were female (see table 1).

Three themes, 'Perceived relational closeness', 'Playing third wheel to axSpA' and 'Tensions surrounding a carertype role' were identified. The themes reflect how the dyads' daily lives had been altered by axSpA through restrictions, changes in relationship strength, and altered partnership roles. Verbatim quotes from participants exemplify the findings. Pseudonyms have been used to both ensure confidentiality of participants and explore the idiographic nature of participant experiences. ${ }^{42} 47$

\section{Perceived relational closeness}

Managing axSpA within a partner relationship had the potential to either enhance dyadic closeness or place greater distance between individuals. Many dyads reported strengthened relationships as a consequence of overcoming the challenges surrounding the condition. This created the sense of a 'team' within relationships. This feeling of enhanced relationship security and unity was perceived to be superior to other healthy couples. This suggests that through shaping relational interactions, axSpA had the capacity to characterise the relationship as something unique:

The sort of bond that we have that way has been kind of strengthened or forged because of needing to [...] be more supportive emotionally $[\ldots]$ we seem as if we show that we care about each other a bit more than your average sort of bloke or woman. Michael (partner)

However, not all partner relationships were cohesive, with the appearance that some partners were pulling against each other. Irritability caused by axSpA symptoms could result in the perception that the other partner did not fully understand their emotions or needs, placing an unwanted division within the relationship:

Sometimes like I'm not as happy as I could be, if I'm a bit tired, you know, and then maybe they say you take it out on the one's you love don't you so you know sort of like a cycle. I like him giving me hugs and kisses but if I'm being a grump I'm not gonna get 'em am I? Rosie (individual with axSpA)

Intimacy was frequently reduced or lost between partners due to the symptoms of axSpA. William and his partner experienced a challenge of "not sharing the bed all the time' (William, partner). Further, Alexander explains:

Sex life vanished quite early on [...] and it isn't something which she can deal with, painkillers are not going to deal with that kind of stress on the body. So, when it all became too painful I just sort of quietly agreed that this is something to stop. Alexander (partner)

Alexander felt a strong sense of reluctance about initiating intimate acts, so as not to cause further pain to his partner. His use of the word 'quietly' reveals a sense of submission to axSpA. This suggests that Alexander's decision to stop sexual activity was not a desired scenario and it was not explicitly acknowledged or discussed with his partner, emphasising a degree of suppressed communication surrounding the challenges of axSpA.

In some cases, this sense of distance was more profound. Bethany's spine 'curvature', caused by axSpA, left her feeling unworthy of her partner which caused her to distance herself from him, resulting in a temporary separation:

I was exhausted I was in a lot of pain, I was tetchy and we did separate for 12 months. And, (partner) did find somebody else he did have an affair, so it's a bit, because I was pushing and pushing away I think because I could not understand why he wanted to be with me anyhow. Bethany (individual with axSpA)

\section{Playing third wheel to axSpA}

To varying degrees, all dyads experienced restrictions within their daily lives. Notably, chronic pain and fatigue could limit the functional abilities of individuals with axSpA, reducing their engagement in leisure time with their partners. This suggests that axSpA could act as a 
Table 1 Participant demographics

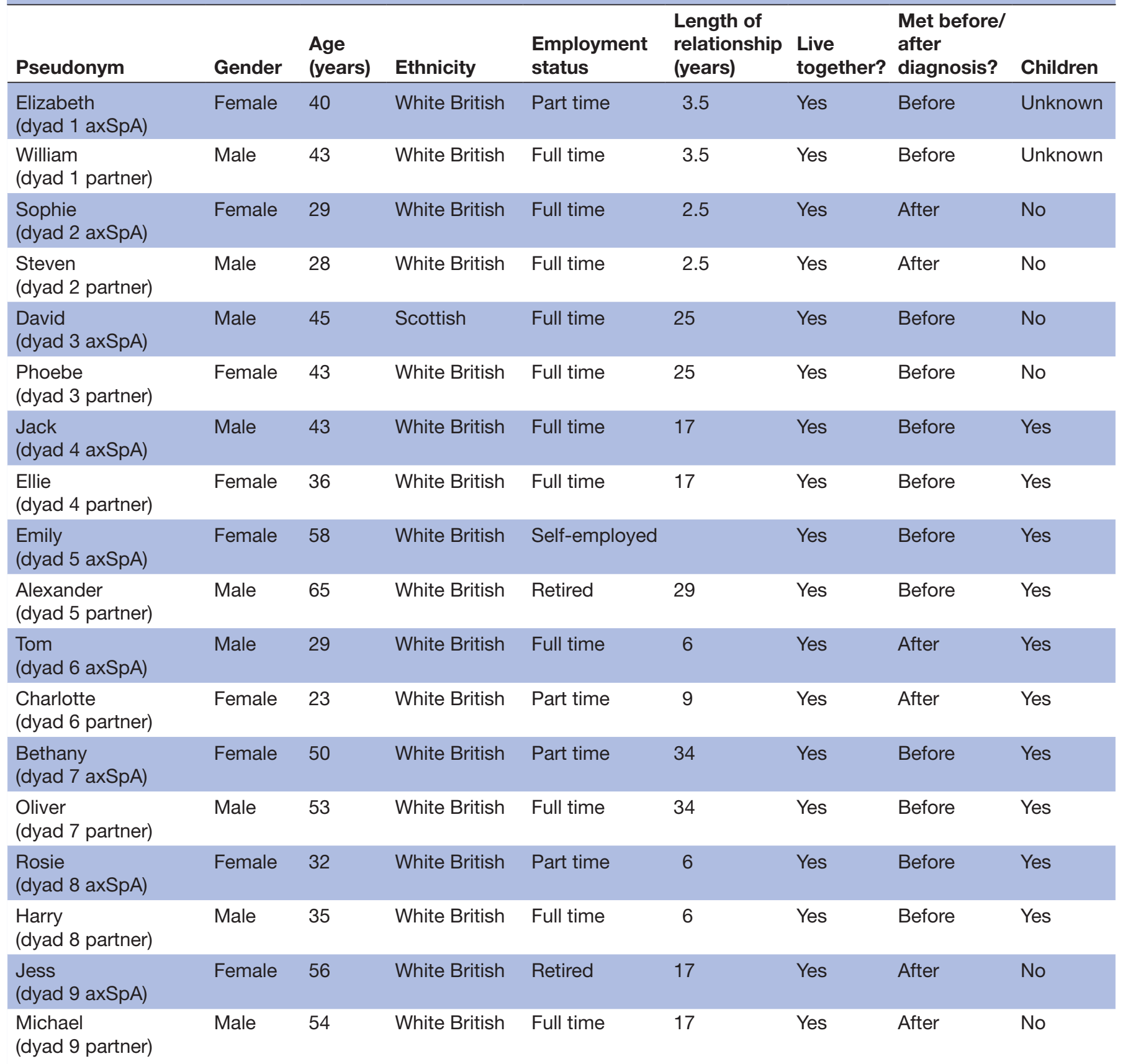

third party within the relationship by placing an obstacle within dyads' social time:

It probably stopped me doing more things with (Ellie) and my kids. (Ellie) takes my son to football at the weekend because she knows I'm not really able to handle sitting or standing around in the cold, things like that. Jack (individual with axSpA)

Making social comparisons to healthy individuals often highlighted dyads' perceived constraints and differences, further emphasising what they were missing out on together as a result of living with axSpA. This reflects a tension between what is desirable and what is possible:
It's what you want to do and you can't do as much as some of your friends are doing and if some people are going away for like a short weekend or finish work on a Friday then they'll go away [...] well (partner's) too tired once he's finished work to go away on a Friday night. Charlotte (partner)

William, contrastingly, perceived a minimal influence of axSpA on his ability to share activities with his partner:

We can still go out walking for 10 miles and things like that so it hasn't really been a major impact on our relationship and the things we want to do together. (William, partner) 
The constant nature of axSpA made life appear effortful for many of the dyads, who adopted joint ownership of managing axSpA. The condition often acted as a central feature which their lives subsequently revolved around, sometimes dominating the partner relationship and pulling behaviours towards managing axSpA over tending to the relationship:

Literally absolutely everything from what we eat, to when we eat, to who does this, to who does that, to when this happens, can it happen? [...] everything is sort of gravitated to AS (referring to Ankylosing Spondylitis, a sub-group of axSpA). Harry (partner)

Dyadic life was portrayed as regimented with a need to plan ahead for activities, reducing spontaneity in their everyday lives. Yet, almost contradictorily, a sudden axSpA flare-up could alter plans at any time: 'if he's feeling really bad then he can't go' (Ellie, Partner)

In addition to joint activity restrictions, many partners experienced a pervading sense of helplessness characterised by limited avenues to relieve their partner's symptoms, exacerbated by the unpredictability of axSpA. Use of the phrase 'miracle worker' illustrates an acknowledging sense of powerlessness against the prevailing condition, further highlighting the dominance of axSpA:

It was a lack of ability to change things which was difficult and it's not that you're looking to be a miracle worker but there aren't even simple things that you could (do) dramatically, the flare-up or change could happen whenever. Oliver (partner)

Despite the ever-present nature of axSpA, some dyads were able to work together to reduce the dominance of the condition on their relationship by making the most out of positive experiences:

We both count our blessings and I hope that, you know, I guess with anything you don't know what's around the corner as well as what's gonna happen to your body. Jess (Individual with axSpA)

\section{Tensions surrounding a carer-type role}

Roles within the relationship were typically adjusted to meet the needs of axSpA. For partners this meant adopting a carer-type role. For a number of individuals, this was an explicit identity, whereas for others this involved a more implicit action of undertaking caregiving behaviours. Supporting partners sometimes proved demanding as demonstrated by Harry below:

She [wife with axSpA] needs to also accept that she's not the only sufferer of AS. You know, there's three people [referring to son too] in this immediate family and actually all of us are suffering as much if not more than she is. Harry (partner)

The word 'sufferer' emotively portrays a sense of hardship from living with axSpA as a partner, which suggests a sense of resentment towards the condition which acted as an impenetrable barrier within the relationship.

For some partners, the carer role extended beyond providing daily support, progressing towards a protector role by managing mood and disease flare-ups which required constant attention. This sense of responsibility to protect was suggestive of an inequitable relationship at times, with the individuals' with axSpA perceived as vulnerable:

I try to keep the mood from falling too far, it's basically a constant it's a constant thing. It shouldn't be and he doesn't ask me to, but I've taken that burden on I think. That's almost my job to make sure he's looking after himself well. Phoebe (partner)

Individuals with axSpA commonly felt guilty relying on their partners, with support focused on the individual with axSpA at the expense of the partners' well-being. In these instances some individuals with axSpA made adjustments to attempt to relieve this burden on their carers:

He [partner] couldn't sleep in bed with me so then it was impacting on him at work so he just goes off and you know sleeps in the spare room and I can wriggle about as much as I like without worrying about disturbing him. Elizabeth (Individual with axSpA)

The notion of dependency for the individuals' with axSpA on their partners was sometimes incompatible with their sense of identity:

I have to sometimes rely on her, like I mean it's like I shouldn't have to really erm but sometimes I have to [...] not a sexist thing, but I'm sort of like the bloke do you know what I mean, so it's like in my head that I'm, I've got to do certain things. Tom (individual with axSpA)

Adopting a carer-role had the capacity to overrule the role of partner, and could result in an element of tension between the individuals' with axSpA seemingly opposing needs for support with managing axSpA and desire to lead a 'normal' life. A line was sometimes crossed where too much help could be offered from partners, contrary to the partners' aims of making life easier for the individuals with axSpA. Sophie desired greater equality within the relationship through demonstrating independence:

Sometimes he tried to do too much and that I'm, he makes me feel like I'm you know useless and not capable and I need help. And I always say to him (Steven) you're not my carer, if I wanted a carer I would have hired a carer. You're my boyfriend, I want you to be my boyfriend, [...] don't try to do everything for me, not let me do stuff myself because you know I want to do those things. Sophie (individual with axSpA)

Self-reliance was also conveyed by the individuals with axSpA through a determination to overcome the physical restrictions of axSpA. This was particularly significant for Emily who desired: 
Empathy. Not sympathy. Sympathy drives me bananas and he knows that. [...]. He occasionally gets it wrong, I remember on, one of the recent challenges, [...] I started getting ankle pain at $45 \mathrm{k}$, checked if it at 52, I could see blood under the skin so I knew that I'd torn something in there. And he said right you're going to see a medic, I said right I'm not, you know me better than that. I strapped it up tight and I did finish the challenge. Emily (individual with axSpA)

\section{DISCUSSION}

This is the first qualitative study to explore the social context of axSpA according to partner dyads, with findings highlighting that couples adopted a joint approach to managing axSpA, which is resonant with the Cognitive Transactional Model of dyadic coping. ${ }^{14}$ Managing axSpA together as a dyad dominated daily decisions and took precedence over shared activities. Study findings demonstrated how axSpA could influence the perceived closeness between partners and consequently, alter the specific characteristics and function of dyadic roles. Tensions could arise between partners' adoption of a carer-type role and individuals' with axSpA desire for autonomy. In order to demonstrate self-reliance some individuals with axSpA refused help from their partners at times which can be perceived as a dyadic coping strategy of withdrawal. ${ }^{15}$ Separate strategies may indicate increases in self-efficacy, as opposed to dyadic efficacy. ${ }^{14}$

Joint leisure time for dyads was often limited which could highlight dyads' sense of loss and difference to other couples. This restriction extended to a reduction in sexual activity, which is a widely acknowledged issue in the axSpA literature. ${ }^{20-22}$ The present study supports and broadens these findings through the inclusion of partner experiences, indicating an element of distance within relationships caused from living with axSpA. Furthermore, consistent with the axSpA literature, ${ }^{19}$ many dyads expressed how their lives typically revolved around condition management.

Moreover, this study uniquely adds to the axSpA literature by clearly detailing the specific and unique nature of the demands perceived by partners of individuals with axSpA; namely to provide a constant source of support, both emotionally and physically, to their partner with axSpA. Additionally, findings are novel in terms of identifying how overcoming the challenges of axSpA together resulted in dyads perceiving strengthened relationships and enhanced closeness. The use of an idiographic approach to the study of dyadic relationships resulted in new knowledge concerning the specific nature of the challenges faced by couples in the context of living with axSpA and how dyads attempt to manage such challenges. This positive change in relational quality can be understood within the context of dyadic coping. Appraisal of axSpA as a shared experience may have increased dyads' confidence in their ability to effectively work together. ${ }^{14}$
Improvements in pain, depression, and marital functioning have been identified in individuals with long-term health conditions, from partner dyadic interventions. ${ }^{48}$ Couple-based interventions have also identified lessened feelings of caregiver burden and anxiety within spouses. ${ }^{49} 50$ Due to the effectiveness of dyadic interventions in other long-term health conditions, ${ }^{48-50}$ there is a clear argument for extending partners' involvement and support provision within healthcare consultations. Such changes may reduce the divide between partners' carer-type role and the individuals' with axSpA desire for autonomy, potentially resulting in a reduction in daily life restrictions within dyads.

The study has several limitations. As all couples were heterosexual and White British the experiences may not be applicable to other types of couples. Moreover, all participants in this study had sought support from the axSpA-specific charity through social media, suggesting that participants may have greater perceived support needs and/or a more aggressive disease trajectory than individuals with axSpA who did not make contact with the axSpA charity's social media pages. Additionally, users of the axSpA-specific charity's social media pages may be more inclined to share their experiences than non-users. Nevertheless, social media has been usefully applied as an acceptable recruitment method within health research. ${ }^{51}$ Telephone interviews usefully facilitated the discussion of a sensitive topic about partner relationships within the context of axSpA, providing rich insight. ${ }^{33}{ }^{34}$ However, it is recognised that visual communication, such as facial expressions, are absent during telephone interviews, which may potentially limit interaction and rapport building. ${ }^{52}{ }^{53}$ Yet, to our knowledge there is no evidence that the quality of data is limited when interviews are conducted via telephone. ${ }^{54}$ Additionally, this study did not collect data on individuals' medication use and self-reported disease activity. As some treatments can markedly improve symptoms of axSpA, it is important that future research addresses differences in treatment between individuals with axSpA and how this may impact on the quality and nature of their partner relationships. Future research should also examine how a pre-existing relationship becomes affected by the onset of axSpA against a newly formed relationship as they may present important yet differing challenges. Despite these limitations, a key strength of the study concerns its use of qualitative methods to enable an in-depth exploration of partner relationships, thus meeting an important knowledge gap.

In conclusion, as the first qualitative study to adopt a dyadic approach to studying the impact of axSpA on partner relationships, study findings highlighted the importance of adopting an interpersonal approach when treating individuals with axSpA. All dyads experienced difficulty with managing axSpA, from activity restrictions to changes in relational strength and altered relational roles. Specifically, findings identified a need to provide support which meets the needs of both individuals with 
axSpA and their partners. Information should be provided to educate and prepare partner dyads about axSpA's potential impact on relationships and effective methods of dyadic coping and thought given to more extensively including partners in treatment where appropriate.

Acknowledgements The authors would like to thank all of the participants for kindly taking the time to share their stories with us and the relevant axSpA-based charity for facilitating the recruitment process.

Contributors The project was conducted as part of a Masters in Health Psychology dissertation under the supervision of AJ and HF. KR, AJ, HF and RS made substantial contributions to the study design, interpretation of the findings for the study, manuscript writing and article revision. AJ and RS contributed to the conception of the study. KR contributed to the collection of data and data analyses, with detailed feedback provided by AJ and HF. All authors read and approved the final version of the manuscript.

Funding The authors have not declared a specific grant for this research from any funding agency in the public, commercial or not-for-profit sectors.

Competing interests HF has received consultancy fees from Astra Zeneca (in 2016) to produce educational materials on medicine errors. RS has received speaker fees, consultancy and/or grants from Abbvie, Celgene, MSD, Novartis, Pfizer and UCB.

Patient consent for publication Not required.

Ethics approval The project was reviewed and approved by a delegated authority from the University of Bath Psychology Department Ethics Committee.

Provenance and peer review Not commissioned; externally peer reviewed.

Data sharing statement № additional data are available.

Open access This is an open access article distributed in accordance with the Creative Commons Attribution Non Commercial (CC BY-NC 4.0) license, which permits others to distribute, remix, adapt, build upon this work non-commercially, and license their derivative works on different terms, provided the original work is properly cited, appropriate credit is given, any changes made indicated, and the use is non-commercial. See: http://creativecommons.org/licenses/by-nc/4.0/.

\section{REFERENCES}

1. Sieper J, Poddubnyy D. Axial spondyloarthritis. Lancet 2017;390:73-84.

2. Coates LC, Tillett W, Chandler D, et al. The 2012 BSR and BHPR guideline for the treatment of psoriatic arthritis with biologics. Rheumatology 2013;52:1754-7.

3. Sengupta R, Stone MA. The assessment of ankylosing spondylitis in clinical practice. Nat Rev Rheumatol 2007.

4. Feldtkeller E, Khan MA, van der Heijde D, et al. Age at disease onset and diagnosis delay in HLA-B27 negative vs. positive patients with ankylosing spondylitis. Rheumatol Int 2003;23:61-6.

5. Martindale J, Smith J, Sutton CJ, et al. Disease and psychological status in ankylosing spondylitis. Rheumatology 2006;45:1288-93.

6. Leverment S, Clarke E, Wadeley A, et al. Prevalence and factors associated with disturbed sleep in patients with ankylosing spondylitis and non-radiographic axial spondyloarthritis: a systematic review. Rheumatol Int 2017;37:257-71.

7. Solmaz M, Binbay Z, Cidem M, et al. Alexithymia and selfesteem in patients with ankylosing spondylitis. Noro Psikiyatr Ars 2014:51:350-4

8. Ward MM. Predictors of the progression of functional disability in patients with ankylosing spondylitis. J Rheumatol 2002;29:1420-5.

9. Salaffi F, Carotti M, Gasparini S, et al. The health-related quality of life in rheumatoid arthritis, ankylosing spondylitis, and psoriatic arthritis: a comparison with a selected sample of healthy people. Health Qual Life Outcomes 2009;7:25.

10. Zink A, Braun J, Listing J, et al. Disability and handicap in rheumatoid arthritis and ankylosing spondylitis--results from the German rheumatological database. German Collaborative Arthritis Centers. J Rheumatol 2000;27:613-22

11. Holtzman S, Delongis A. One day at a time: the impact of daily satisfaction with spouse responses on pain, negative affect and catastrophizing among individuals with rheumatoid arthritis. Pain 2007;131:202-13.
12. Riemsma RP, Taal E, Rasker JJ. Perceptions about perceived functional disabilities and pain of people with rheumatoid arthritis: differences between patients and their spouses and correlates with well-being. Arthritis Care Res 2000;13:255-61.

13. Checton MG, Magsamen-Conrad K, Venetis MK, et al. A dyadic approach: applying a developmental-conceptual model to couples coping with chronic illness. Health Educ Behav 2015;42:257-67.

14. Badr H, Acitelli LK. Re-thinking dyadic coping in the context of chronic illness. Curr Opin Psychol 2017;13:44-8.

15. Berg CA, Upchurch R. A developmental-contextual model of couples coping with chronic illness across the adult life span. Psychol Bull 2007;133:920-54.

16. Bodenmann G. Dyadic coping and its significance for marital functioning. Couples coping with stress: Emerging perspectives on dyadic coping. Washington, DC: American Psychological Association, 2005:33-50.

17. Arden-Close E, McGrath N. Health behaviour change interventions for couples: A systematic review. British J Health Psychol 2017.

18. Madsen M, Jensen KV, Esbensen BA. Men's experiences of living with ankylosing spondylitis: a qualitative study. Musculoskeletal Care 2015;13:31-41.

19. Bagcivan $\mathrm{G}$, Cinar FI, Cinar M, et al. Living with pain in ankylosing spondylitis: a qualitative study. Contemp Nurse 2015;51:135-47.

20. Healey EL, Haywood KL, Jordan KP, et al. Ankylosing spondylitis and its impact on sexual relationships. Rheumatology 2009;48:1378-81.

21. Akkurt HE, Yilmaz H, Yilmaz $\mathrm{S}$, et al. Evaluation of sexual dysfunction in females with ankylosing spondylitis. Arch Rheumatol 2016;31:41-7.

22. Akkuș Y, Nakas D, Kalyoncu U. Factors affecting the sexual satisfaction of patients with rheumatoid arthritis and ankylosing spondylitis. Sex Disabil 2010;28:223-32.

23. Hamilton-West KE, Quine L. Living with ankylosing spondylitis: the patient's perspective. J Health Psychol 2009;14:820-30.

24. Van Genderen S, Plasqui G, Landewé R, et al. Social role participation in patients with ankylosing spondylitis: a crosssectional comparison with population controls. Arthritis care res 2016.

25. Uludag M, Unalan $\mathrm{H}$, Tuzun $\mathrm{S}$, et al. Assessment of quality of life and depression in spouses of patients with ankylosing spondylitis. Rheumatol Int 2012;32:3511-6.

26. In: Camic PM, Rhodes JE, Yardley L, eds. Qualitative research in psychology: expanding perspectives in methodology and design. Washington, DC: American Psychological Association, 2003.

27. Hodgson JH, Garcia K, Tyndall L. Parkinson's disease and the couple relationship: a qualitative analysis. Fam Syst Health 2004.

28. Kayser K, Watson LE, Andrade JT. Cancer as a" we-disease" examining the process of coping from a relational perspective. Fam Syst Health 2007

29. McCluskey S, Brooks J, King N, et al. The influence of 'significant others' on persistent back pain and work participation: a qualitative exploration of illness perceptions. BMC Musculoskelet Disord 2011;12:236.

30. Saunders B, Sim J, Kingstone T, et al. Saturation in qualitative research: exploring its conceptualization and operationalization. Qual Quant 2018;52:1893-907.

31. Guest G, Bunce A, Johnson L. How many interviews are enough? An experiment with data saturation and variability. Field Methods 2006.

32. Legard R, Keegan J, Ward K. In-depth interviews. In: Ritchie J, Lewis J, eds. Qualitative research practice: a guide for social science students and researchers. London, UK: Sage, 2003:139-69.

33. Sturges JE, Hanrahan KJ. Comparing telephone and face-to-face qualitative interviewing: a research note. Qualitative Research 2004;4:107-18.

34. Trier-Bieniek A. Framing the telephone interview as a participantcentred tool for qualitative research: a methodological discussion. Qualitative Research 2012;12:630-44.

35. Hamilton L, Macgregor A, Toms A, et al. The prevalence of axial spondyloarthritis in the UK: a cross-sectional cohort study. BMC Musculoskelet Disord 2015;16:392.

36. Morris SM. Joint and individual interviewing in the context of cancer. Qual Health Res 2001;11:553-67.

37. Smith JA. Semi-structured interviewing and qualitative analysis. In: Smith AJ, Harre R, Van Lagenhove L, eds. Rethinking methods in psychology. London, UK: Sage, 1995.

38. Kvale S, Brinkmann S. Interviews: Learning the craft of qualitative research interviewing. Thousand Oaks, CA: Sage, 2009.

39. Gillham B. Research interviewing: the range of techniques: a practical guide. UK: McGraw-Hill Education, 2005.

40. NVivo Version 11.

41. Braun V, Clarke V. Using thematic analysis in psychology. Qual Res Psychol 2006;3:77-101. 
42. Braun V, Clarke V. Successful qualitative research: a practical guide for beginners. London, UK: Sage, 2013.

43. Gilgun JF. Beyond description to interpretation and theory in qualitative social work research. Qualitative Social Work 2015.

44. Eisikovits Z, Koren C. Approaches to and outcomes of dyadic interview analysis. Qual Health Res 2010;20:1642-55.

45. Tong A, Sainsbury P, Craig J. Consolidated criteria for reporting qualitative research (COREQ): a 32-item checklist for interviews and focus groups. Int J Qual Health Care 2007;19:349-57.

46. Yardley L. Dilemmas in qualitative health research. Psychol Health 2000.

47. Kaiser K. Protecting respondent confidentiality in qualitative research. Qual Health Res 2009;19:1632-41.

48. Martire LM, Schulz R, Helgeson VS, et al. Review and meta-analysis of couple-oriented interventions for chronic illness. Ann Behav Med 2010;40:325-42.
49. Martire LM, Lustig AP, Schulz R, et al. Is it beneficial to involve a family member? A meta-analysis of psychosocial interventions for chronic illness. Health Psychol 2004;23:599-611.

50. Hartmann M, Bäzner E, Wild B, et al. Effects of interventions involving the family in the treatment of adult patients with chronic physical diseases: a meta-analysis. Psychother Psychosom 2010;79:136-48.

51. Whitaker C, Stevelink S, Fear N. The use of facebook in recruiting participants for health research purposes: a systematic review. $J$ Med Internet Res 2017;19:e290.

52. Irvine A, Drew P, Sainsbury R. 'Am I not answering your questions properly?' Clarification, adequacy and responsiveness in semistructured telephone and face-to-face interviews. Qualitative Research 2013;13:87-106.

53. Sweet L. Telephone interviewing: is it compatible with interpretive phenomenological research? Contemp Nurse 2002;12:58-63.

54. Novick G. Is there a bias against telephone interviews in qualitative research? Res Nurs Health 2008;31:391-8. 